\title{
Naringenin Attenuated Prostate Cancer Invasion via Reversal of Epithelial-to-Mesenchymal Transition and Inhibited uPA Activity
}

\author{
KUEI-YANG HAN ${ }^{1 *}$, PEI-NI CHEN ${ }^{2 *}$, MING-CHIAN HONG ${ }^{2}$, YOU-CHENG HSEU ${ }^{3}$, \\ KE-MING CHEN ${ }^{4}$, LI-SUNG HSU ${ }^{2,5}$ and WEI-JEN CHEN ${ }^{6,7}$ \\ ${ }^{1}$ Department of Family Medicine, Jen-Ai Hospital, Taichung, Taiwan, R.O.C.; \\ ${ }^{2}$ Institute of Biochemistry, Microbiology and Immunology, \\ Chung Shan Medical University, Taichung, Taiwan, R.O.C; \\ ${ }^{3}$ Department of Cosmeceutics, College of Pharmacy, China Medical University, Taichung, Taiwan, R.O.C; \\ ${ }^{4}$ Department of Parasitology School of Medicine, Chung Shan Medical University, Taichung, Taiwan, R.O.C; \\ ${ }^{5}$ Clinical Laboratory, Chung Shan Medical University Hospital, Taichung, Taiwan, R.O.C; \\ ${ }^{6}$ Department of Medical Research, Chung Shan Medical University Hospital, Taichung, Taiwan, R.O.C; \\ ${ }^{7}$ Department of Biomedical Sciences, Chung Shan Medical University, Taichung, Taiwan, R.O.C.
}

\begin{abstract}
Background: Prostate cancer is highly prevalent with a high mortality among males worldwide. Naringenin has been demonstrated to exhibit multiple cellular functions. In this study, we examined the effects of naringenin on prostate cancer. Materials and Methods: Transwell and zymography assays were used to detect cell migration and urokinase plasminogen activator (uPA) activity, respectively. Alternation of protein expression was measured by western blot analysis. Results: Transwell assay and zymography revealed that naringenin suppressed the migration and invasion of PC-3 cells and UPA activity in proportion to the concentration of naringenin. Western blot analysis indicated that naringenin up-regulated E-cadherin expression, but down-regulated the expression of vimentin, SNAIL family zinc finger 1 (SNAI1), SNAIL family zinc finger 2 (SNAI2), and TWIST family bHLH transcription factor 1 (TWIST1).
\end{abstract}

\footnotetext{
*These Authors contributed equally to this study.

Correspondence to: Li-Sung Hsu, Ph.D., Institutes of Biochemistry, Microbiology, and Immunology, Chung Shan Medical University, No. 110, Sec. 1, Jianguo N. Road, Taichung, 40201, Taiwan, R.O.C. Tel: +886424730022 ext. 11682 , Fax: +886 423248195, e-mail: 1sh316@csmu.edu.tw and Wei-Jen Chen, Ph.D., Department of Biomedical Sciences, Chung Shan Medical University, No. 110, Sec. 1, Jianguo N. Road, Taichung, 40201, Taiwan, R.O.C. Tel: +886 424730022 ext. 11682, Fax: +886 423248187, e-mail: cwj519@csmu.edu.tw
}

Key Words: Prostate cancer, migration, invasion, urokinase plasminogen activator, naringenin.
Conclusion: Naringenin inhibited the migration and invasion of PC-3 cells by reversing expression of proteins involved in epithelial-to-mesenchymal transition and down-regulation of uPA activity. Thus, naringenin may be a promising antimetastasis agent for prostate cancer.

Prostate cancer is the second leading cause of cancer-related death among men in Western countries (1). The 5-year survival rate dramatically decreases when cancer becomes invasive and metastasizes. Therefore, the development of non-toxic agents to retard prostate tumor migration and invasion is urgently needed.

Epithelial-to-mesenchymal transition (EMT) plays a critical role in embryotic development, wound healing, cancer metastasis, and drug resistance $(2,3)$. During EMT, cancer cells lose their epithelial characteristics, such as cell-cell adhesion and polarity, and gain mesenchymal phenotypes to facilitate their migration and invasion (2, 3). Several transcriptional factors, such as SNAIL family zinc finger 1 (SNAI1), SNAI2, and TWIST family bHLH transcription factor 1 (TWIST1) are involved in the EMT (2). These transcriptional factors can bind to the promoter region and suppress the expression of E-cadherin, an epithelial marker for cell-cell adhesion (4). However, these transcriptional factors up-regulate the expression of mesenchymal markers, such as vimentin and $\mathrm{N}$-cadherin (4). E-cadherin expression was lost in prostate cancer with high grade and poor progression (5). By contrast, SNAI1 expression was higher in prostate cancer samples with advanced grade (6). The overexpression of TWIST1 is an independent prognostic factor for the recurrence-free survival of patients with prostate cancer (7). 
Naringenin, a bioactive compound in grapefruit and orange, exhibits many cellular effects, such as anticancer, anti-inflammation, and anti-atherogenic effects (8). The treatment of bladder cancer and lung cancer cells with naringenin has been shown to inhibit migration by reducing matrix metalloproteinase 2 (MMP2) and MMP9 activities and protein kinase B (PKB/AKT) $(9,10)$. Very recently, Lim et al. (11) demonstrated that naringenin induced apoptosis through a mitochondrial-dependent pathway and modulated extracellular signal-regulated kinase (ERK) and AKT activities in PC3 and LNCaP prostate cancer cells. In addition, naringenin inhibited prostate cancer migration by regulating of voltage-gated sodium channels (12). To the best of our knowledge, although the effects of naringenin have been demonstrated in several human cancer types, its effects on prostate cancer migration and the mechanisms underlying these effects remain to be elucidated.

\section{Materials and Methods}

Cells and reagents. The PC-3 human prostate cancer cells were purchased from American Type Culture Collection (ATCC, Manassas, VA, USA). The PC-3 cells were cultured in RPMI- 1640 medium supplemented with $10 \%$ fetal bovine serum, 100 units $/ \mathrm{ml}$ of penicillin, and $100 \mu \mathrm{g} / \mathrm{ml}$ of streptomycin at $37^{\circ} \mathrm{C}$ and incubated under 5\% CO2. Antibodies against E-cadherin, vimentin, SNAI1, SNAI2, and TWIST1 were obtained from Santa Cruz (Santa Cruz, CA, USA). All chemicals were obtained from Sigma-Aldrich (St. Louis, MO, USA).

Cell viability assay. PC-3 cells were seeded in 24-well plates at a density of $2 \times 10^{4} / \mathrm{ml}$ and treated with $0,25,50,100,200$, and $300 \mu \mathrm{M}$ naringenin for 24,48 , and $72 \mathrm{~h}$. The cells were subsequently treated with $5.0 \mathrm{~g} / \mathrm{I}$ 3-(4,5dimethylthiazol-2-xyl)-2,5 diphenyl-tetrazolium bromide (MTT) and incubated at $37^{\circ} \mathrm{C}$ for an additional $2.5 \mathrm{~h}$. The purplish-blue sediments were dissolved in $1 \mathrm{ml}$ of isopropanol, and the absorbance was determined at $563 \mathrm{~nm}$. Based on the absorbance, cell viability was expressed as a percentage of control from three independent experiments.

Migration and invasion assay. PC-3 cells were treated with 0, 25, $50,100,200$, and $300 \mu \mathrm{M}$ concentration of naringenin for $48 \mathrm{~h}$. The cells were detached by trypsin and plated into the upper section of a 48-well Boyden chamber at a density of $2.5 \times 10^{4} / \mathrm{ml}$. After incubation at $37^{\circ} \mathrm{C}$ for $16 \mathrm{~h}$, the migrated cells were fixed with methanol and stained with Giemsa solution. For the invasion assay, the upper section of the Boyden chamber was coated with Matrigel $\left(100 \mu \mathrm{g} / \mathrm{cm}^{2}\right)$, and the incubation time was $24 \mathrm{~h}$. Three fields of each chamber were randomly selected, and the cell numbers were counted under a microscope.

Zymography assay. PC-3 cells were incubated with serum-free RPMI-1640 medium containing 0, 25, 50, 100, 200, and $300 \mu \mathrm{M}$ naringenin for $24 \mathrm{~h}$. The conditioned media were collected and subjected to zymography assay to detect uPA activity as previously reported (13).

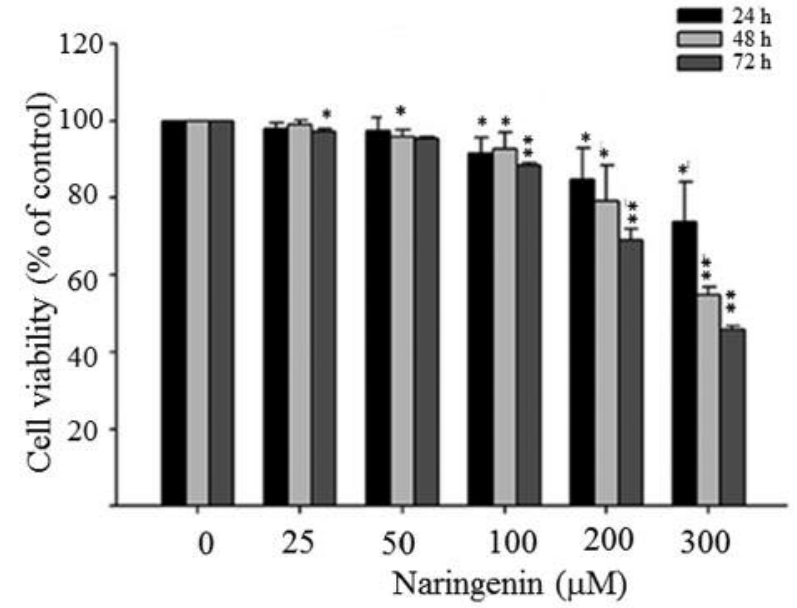

Figure 1. Naringenin inhibited prostate cancer cell viability. PC-3 Human prostate cancer cells were treated with the indicated concentrations of Naringenin for 24,48 , and $72 \mathrm{~h}$. Cell viability was measured by the MTT assay. Data represent means \pm S.D. from at least three independent experiments. Significantly different from the control $(0 \mu M)$ at $* p<0.05$ and $* * p<0.001$.

Western blot analysis. PC-3 cells were treated with 0, 25, 50, 100, 200 , and $300 \mu \mathrm{M}$ concentrations of naringenin for $48 \mathrm{~h}$. Cell lysates were collected, and an equal amount of proteins $(50 \mu \mathrm{g})$ was separated by sodium dodecyl sulfate-polyacrylamide gel electrophoresis and blotted to determine EMT-related proteins, as described in a previous report (10).

Statistical analysis. The reported data are expressed as mean \pm standard deviation of three independent experiments and were evaluated by Student's $t$-test using SPSS software (Armonk, NY, USA). Differences with $p$-values less than 0.05 were considered to be statistically significant.

\section{Results}

MTT assay was performed to detect the effects of naringenin on the proliferation of PC-3. The cells were treated with different concentrations of naringenin for 24,48 , and $72 \mathrm{~h}$. Compared with the vehicle-treated group, naringenin significantly reduced cell viability in a dose- and timedependent manner (Figure 1). These findings suggest that naringenin reduced the proliferation of PC-3 cells.

A previous report showed that naringenin abolished the migration of MAT-LyLu prostate cells (12). Transwell assay was performed to determine whether naringenin reduced the migration and invasion of PC-3. The PC-3 cells were pretreated with $25,50,100,200$, and $300 \mu \mathrm{M}$ of naringenin for $48 \mathrm{~h}$. Equal amounts of alive cells were plated in the upper chamber, and migration and invasion were detected after $16 \mathrm{~h}$. Treatment with naringenin significantly reduced cell 
A

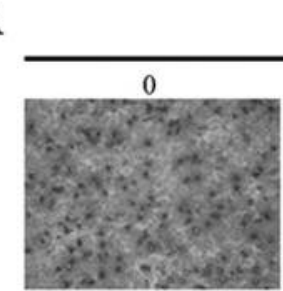

100

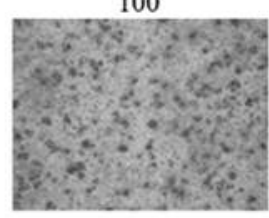

B
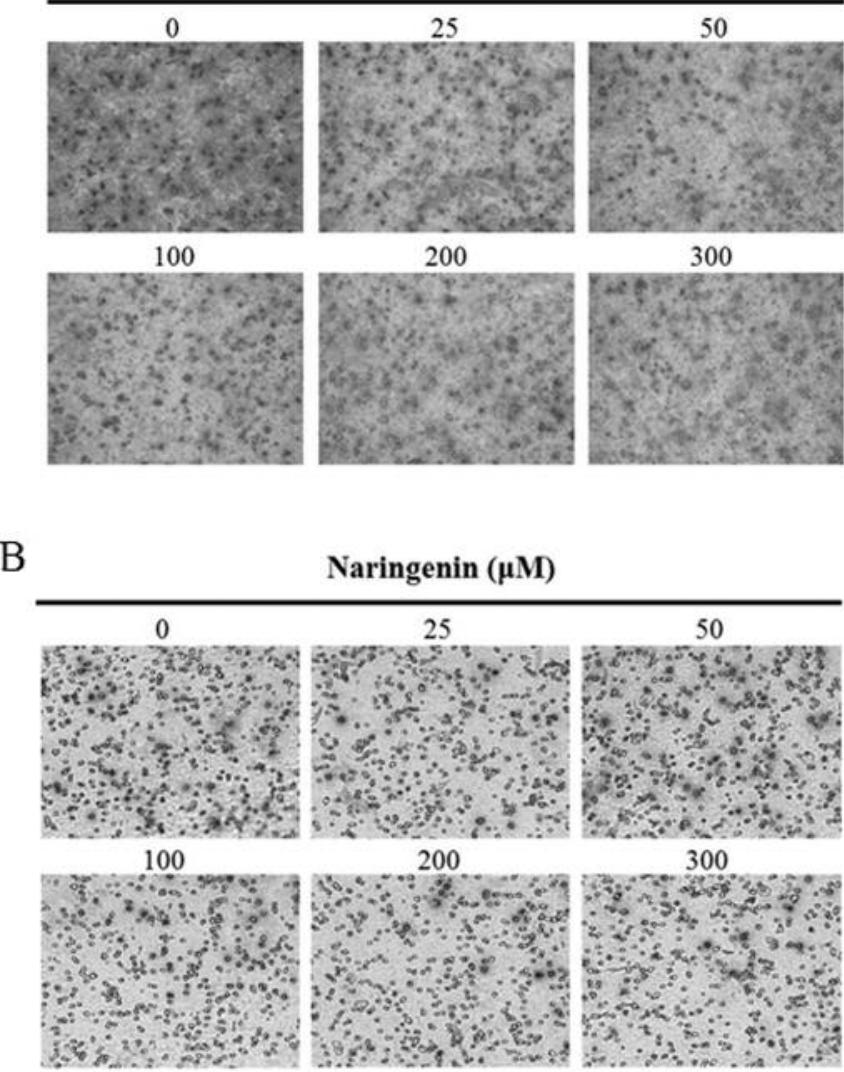

200
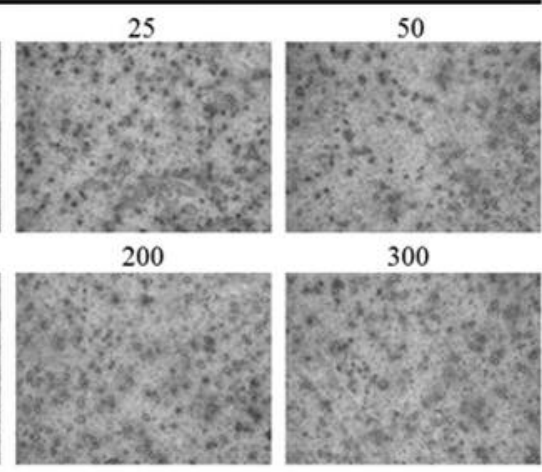

Naringenin $(\mu \mathrm{M})$
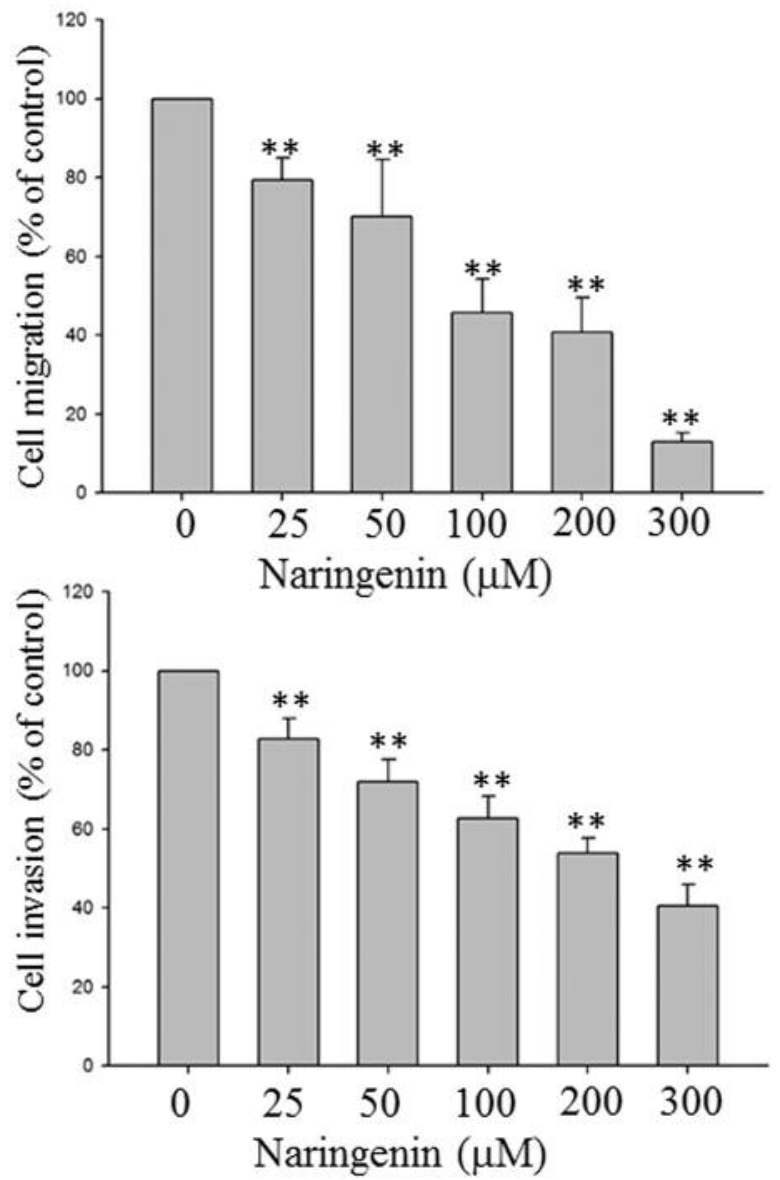

Figure 2. Naringenin inhibited migration (A) and invasion (B) of PC-3 cells. Migration and invasion were assayed by Boyden chamber as mentioned in the Materials and Methods section. Data represent means \pm S.D. from at least three independent experiments. Significantly different from the control $(0 \mu M)$ at $* p<0.05$.

migration compared with the vehicle-treated group (Figure 2). The invasive ability was also significantly reduced response to naringenin (Figure 2). Naringenin dose-dependently inhibited the migration and invasion of PC-3 cells.

Cancer cells can secrete high levels of uPA to degrade the extracellular matrix for their migration and invasion (14). A zymography assay was conducted to test whether naringenin also affected uPA activity. In the presence of 25, 50, 100, 200 , and $300 \mu \mathrm{M}$ naringenin, the uPA activities were reduced to around $75 \%$ compared with that in the vehicle-treated group (Figure 3).

EMT has a critical role in cell migration (2). Thus, western blot analysis was performed to test whether naringenin affected the expression of EMT-related proteins. Exposure to $300 \mu \mathrm{M}$ naringenin significantly up-regulated Ecadherin expression, whereas low concentrations of naringenin had no effects on E-cadherin expression (Figure
4). By contrast, expression of mesenchymal markers, namely, SNAI1, SNAI2, TWIST1, and vimentin, was reduced in proportion to the concentration of naringenin. Therefore, naringenin appears to reverse EMT.

\section{Discussion}

Given its high metastatic ability, it is surprising that prostate cancer is one of the leading causes of cancer-related deaths among men worldwide. The anti-metastatic effects of extracts derived from dietary foods have recently received great attention. In this study, we demonstrated that naringenin diminished the migration of PC-3 cells by inhibiting uPA activity, down-regulating expression of mesenchymal-like markers, and up-regulating E-cadherin.

In this study, we demonstrated that naringenin significantly attenuated migration and invasion of PC-3 cells. Our 

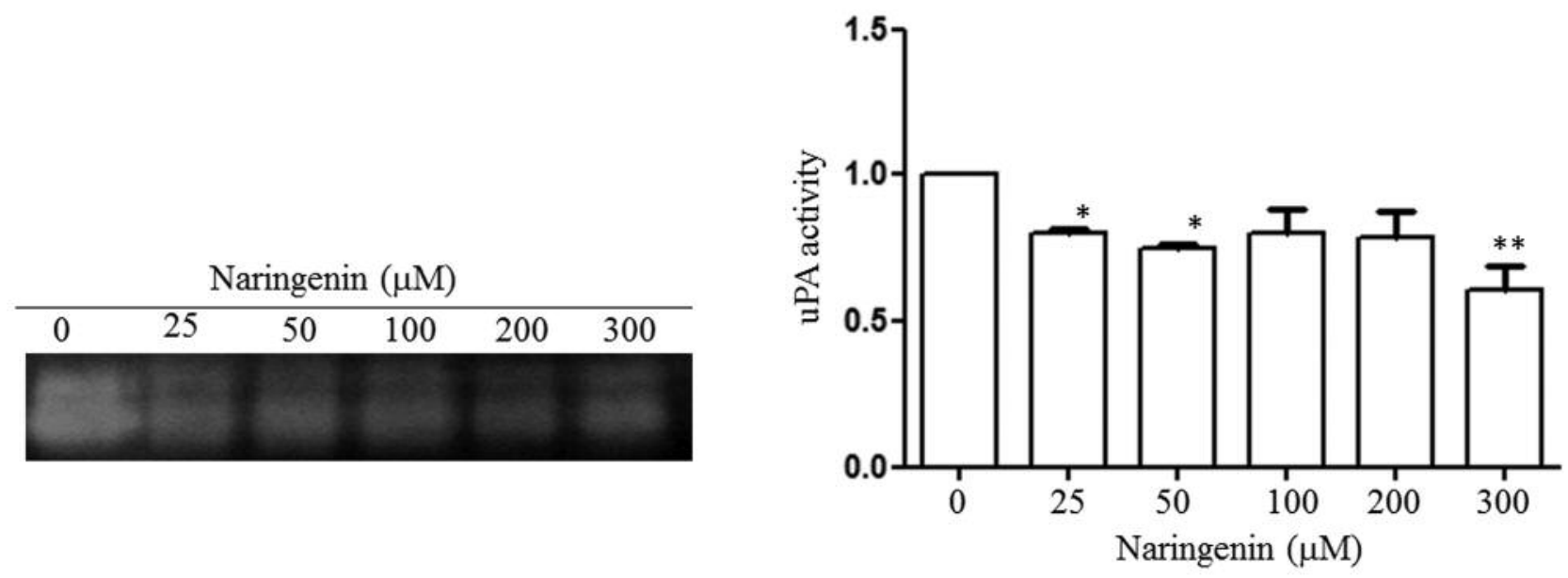

Figure 3. Naringenin reduced urokinase plasminogen activator (uPA) activity. PC-3 cells were treated with indicated concentration of naringenin in serum-free medium for $24 \mathrm{~h}$. Conditional serum was collected and subjected into casein zymography analysis. Casein data represent means $\pm S . D$. from at least three independent experiments. Significantly different from the control $(0 \mu M)$ at $* p<0.05$ and $*^{*} p<0.001$.

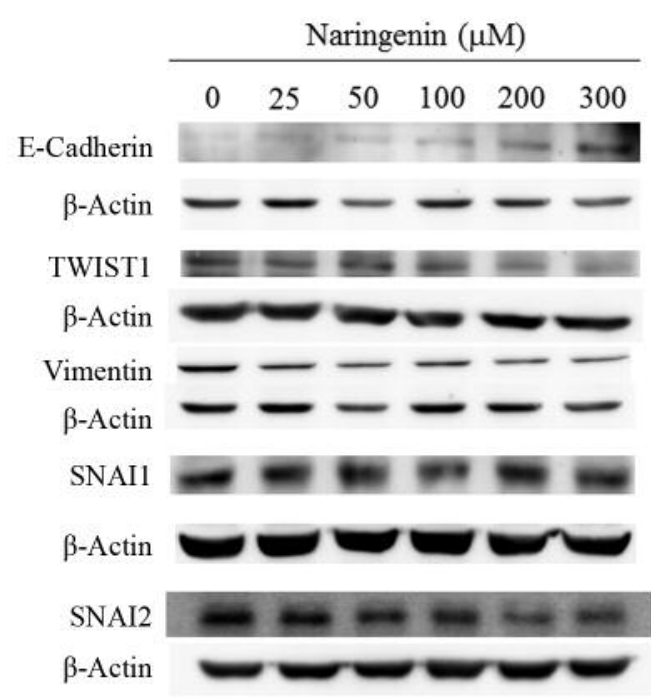

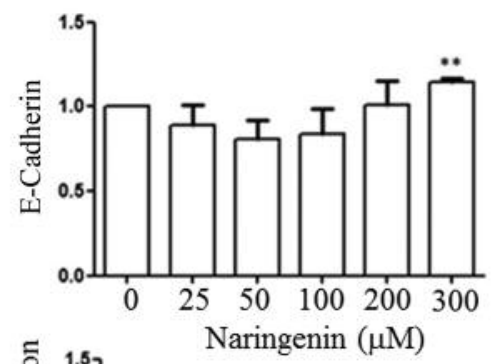
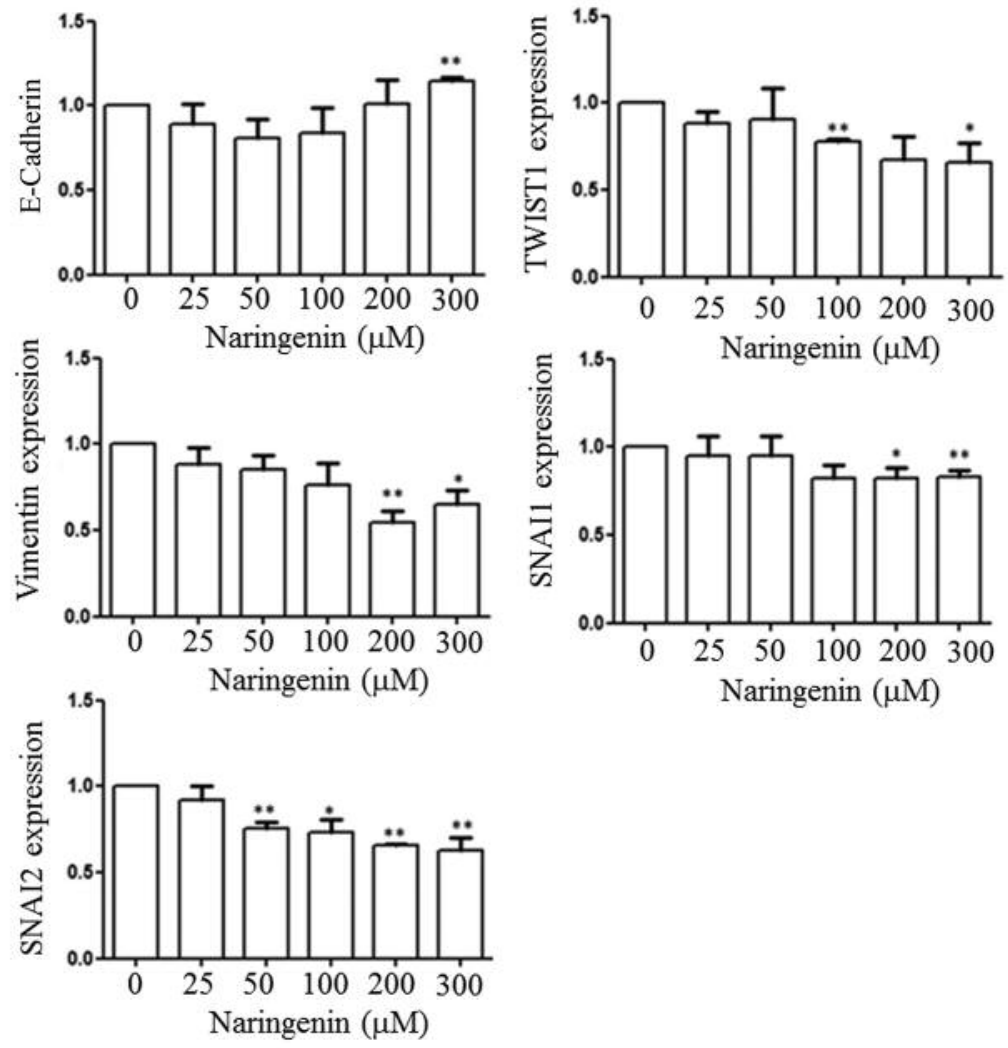

Figure 4. Naringenin reversed the expression of epithelial-to-mesenchymal transition markers. PC-3 cells were exposed to the indicated concentration of naringenin for $48 \mathrm{~h}$. Cell lysates were extracted and western blot analysis was performed and using antibodies against E-cadherin (epithelial marker) and mesenchymal markers SNAIL family zinc finger 1 (SNAI1), SNAI2, TWIST family bHLH transcription factor 1 (TWIST1), vimentin, and TWIST1. Data represent means \pm S.D. from at least three independent experiments. Significantly different from the control $(0 \mu M)$ at $* p<0.05$ and $* * p<0.001$. 
observations are in line with that of Gumushan Aktas and Akgun whereby naringenin (5 and $10 \mu \mathrm{M}$ ) diminished migration of MAT-LyLu prostate cancer cells, accompanied with inhibition of voltage-gated sodium channel SCN9A expression (12). Lim et al. demonstrated that naringenin at $50 \mu \mathrm{M}$ reduced the migration of $\mathrm{PC}-3$, but not $\mathrm{LNCaP}$ cells (11). Controversially, naringenin at 5, 10, 20, 50, and $100 \mu \mathrm{M}$ reduced cell viability of serum-starved PC-3 cells and LNCaP cells (11). In contrast, our results indicated that naringenin slightly reduced cell viabilities only at 100,200 , and $300 \mu \mathrm{M}$ concentrations. This difference in observations between the present study and those of Lim et al. (11) might result from an increase inPC-3 cell sensitivity to naringenin treatment after serum starvation. Collectedly, our findings indicated that naringenin inhibited migration and invasion of PC-3 cells.

The degradation of the extracellular matrix by proteinases, such as MMPs and uPA, has a critical role in the migration and invasion of cancer cells (15). Through immunohistochemical staining, Kumano et al. demonstrated that uPA expression was correlated with advanced stages and lymph node metastasis in prostate cancer (16). Several extracts from dietary foods were recently shown to have anti-metastatic effects on prostate cancer. Epigallocatechin gallate, a polyphenol in green tea, cooperated with tumor necrosis factor-related apoptosisinducing ligand (TRAIL) to reduce the migration and invasion of prostate cancer cells by down-regulating UPA (17). Quercetin similarly repressed the expression of uPA and subsequently inhibited the migration of PC-3 cells (18). Similarly, our finding indicated that naringenin treatment reduced the activity of uPA as assayed by zymography analysis and subsequently attenuated the migration and invasion of PC-3 cells.

During EMT, cancer cells acquire mesenchymal-like phenotypes to promote their migration and invasion, eventually causing metastasis in secondary organs (19). Transcriptional factors, such as SNAI1, SNAI2, and TWIST1, up-regulate expression of mesenchymal markers and down-regulate that of epithelial markers $(19,20)$. In prostate cancer, SNAI1 expression is associated with Gleason grade (21), and upregulation of SNAII expression has been correlated with the progression of prostate cancer (22). Kwok et al. also demonstrated that TWIST1 expression increased in prostate cancer with bone metastasis (23). Accumulating reports have shown that polyphenols from dietary foods can attenuate the migration of prostate cancer cells by reversing the EMT. Genistein dose-dependently suppressed the invasion of prostate cancer cells by reversing EMT (24). Wu et al. also demonstrated that silibinin enhanced cytokeratin-18 expression and down-regulated vimentin, MMP2, and SNAI2 (25). These processes reduce the metastatic properties of PC-3 cells. Similarly, naringenin treatment up-regulated expression of epithelial markers, such as E-cadherin, and down-regulated the four mesenchymal markers. Moreover, naringenin reversed the EMT and reduced the migration of PC-3 cells.
In conclusion, naringenin attenuated the migration and invasion of PC-3 cells by inhibiting uPA activity, downregulating mesenchymal regulators, namely, SNAII, SNAI2, and TWIST1, and elevating that of epithelial markers, such as E-cadherin. To the best of our knowledge, this is the first report that highlights the molecular mechanisms of naringenin in the migration of PC-3. These results also provide evidence for naringenin as a potential therapeutic agent for the treatment of prostate cancer metastasis.

\section{Conflicts of Interest}

The Authors declared no conflict of interest in regard to this study.

\section{Acknowledgements}

This study was supported by grants obtained from the Ministry of Science and Technology of Taiwan (MOST-103-2311-B-040-001) and CSMU-JAH-104-03.

\section{References}

1 Siegel R, Naishadham D and Jemal A: Cancer statistics, 2013. CA Cancer J Clin 63: 11-30, 2013.

$2 \mathrm{Li} \mathrm{L}$ and $\mathrm{Li} \mathrm{W}$ : Epithelial-mesenchymal transition in human cancer: comprehensive reprogramming of metabolism, epigenetics, and differentiation. Pharmacol Ther 150: 33-46, 2015.

3 Thiery JP, Acloque H, Huang RY and Nieto MA: Epithelialmesenchymal transitions in development and disease. Cell 139: 871-890, 2009.

4 Lamouille S, Xu J and Derynck R: Molecular mechanisms of epithelial-mesenchymal transition. Nat Rev Mol Cell Biol 15: 178-196, 2014.

5 Rao DS, Gui D, Koski ME, Popoviciu LM, Wang H, Reiter RE and Said JW: An inverse relation between COX-2 and E-cadherin expression correlates with aggressive histologic features in prostate cancer. Appl Immunohistochem Mol Morphol 14: 375-383, 2006.

6 Poblete CE, Fulla J, Gallardo M, Munoz V, Castellon EA, Gallegos I and Contreras HR: Increased SNAI1 expression and low syndecan levels are associated with high Gleason grade in prostate cancer. Int J Oncol 44: 647-654, 2014.

7 Raatikainen S, Aaltomaa S, Palvimo JJ, Karja V and Soini Y: TWIST1 overexpression predicts biochemical recurrence-free survival in prostate cancer patients treated with radical prostatectomy. Scand J Urol 49: 51-57, 2015.

8 Zenga W, Jinb L, Zhanga F, Zhanga $C$ and Wei L: Naringenin as a potential immunomodulator in therapeutics. Pharmacol Res 135: 122-126, 2018.

9 Chang HL, Chang YM, Lai SC, Chen KM, Wang KC, Chiu TT, Chang FH and Hsu LS: Naringenin inhibits migration of lung cancer cells via the inhibition of matrix metalloproteinases-2 and-9. Exp Ther Med 13: 739-744, 2017.

10 Liao AC, Kuo CC, Huang YC, Yeh CW, Hseu YC, Liu JY and Hsu LS: Naringenin inhibits migration of bladder cancer cells through downregulation of AKT and MMP2. Mol Med Rep 10: 1531-1536, 2014. 
11 Lim W, Park S, Bazer FW and Song G: Naringenin-induced apoptotic cell death in prostate cancer cells is mediated via the PI3K/AKT and MAPK Signaling Pathways. J Cell Biochem 118 : 1118-1131, 2017.

12 Gumushan Aktas H and Akgun T: Naringenin inhibits prostate cancer metastasis by blocking voltage-gated sodium channels. Biomed Pharmacother 106: 770-775, 2018.

13 Chen PN, Chu SC, Kuo WH, Chou MY, Lin JK and Hsieh YS: Epigallocatechin-3 gallate inhibits invasion, epithelialmesenchymal transition, and tumor growth in oral cancer cells. J Agric Food Chem 59: 3836-3844, 2011.

14 Duffy MJ and Duggan C: The urokinase plasminogen activator system: A rich source of tumour markers for the individualised management of patients with cancer. Clin Biochem 37: 541-548, 2004.

15 Mekkawy AH, Pourgholami MH and Morris DL: Involvement of urokinase-type plasminogen activator system in cancer: an overview. Med Res Rev 34: 918-956, 2014.

16 Kumano M, Miyake H, Muramaki M, Furukawa J, Takenaka A and Fujisawa M: Expression of urokinase-type plasminogen activator system in prostate cancer: correlation with clinicopathological outcomes in patients undergoing radical prostatectomy. Urol Oncol 27: 180-186, 2009.

17 Siddiqui IA, Malik A, Adhami VM, Asim M, Hafeez BB, Sarfaraz S and Mukhtar H: Green tea polyphenol EGCG sensitizes human prostate carcinoma LNCaP cells to TRAILmediated apoptosis and synergistically inhibits biomarkers associated with angiogenesis and metastasis. Oncogene 27: 2055-2063, 2008.

18 Senthilkumar K, Arunkumar R, Elumalai P, Sharmila G, Gunadharini DN, Banudevi S, Krishnamoorthy G, Benson CS and Arunakaran J: Quercetin inhibits invasion, migration and signalling molecules involved in cell survival and proliferation of prostate cancer cell line (PC-3). Cell Biochem Funct 29: 87-95, 2011.
19 Nauseef JT and Henry MD: Epithelial-to-mesenchymal transition in prostate cancer: Paradigm or puzzle? Nat Rev Urol 8: 428-439, 2011.

20 Smith BN and Odero-Marah VA: The role of SNAI1 in prostate cancer. Cell Adh Migr 6: 433-441, 2012.

21 Heeboll S, Borre M, Ottosen PD, Dyrskjot L, Orntoft TF and Torring N: SNAI11 is over-expressed in prostate cancer. APMIS 117: 196-204, 2009.

22 Odero-Marah VA, Wang R, Chu G, Zayzafoon M, Xu J, Shi C, Marshall FF, Zhau HE and Chung LW: Receptor activator of NF-kappaB ligand (RANKL) expression is associated with epithelial to mesenchymal transition in human prostate cancer cells. Cell Res 18: 858-70, 2008.

23 Kwok WK, Ling MT, Lee TW, Lau TC, Zhou C, Zhang X, Chua CW, Chan KW, Chan FL, Glackin C, Wong YC and Wang X: Up-regulation of TWIST1 in prostate cancer and its implication as a therapeutic target. Cancer Res 65: 5153-5162, 2005.

24 Zhang LL, Li L, Wu DP, Fan JH, Li X, Wu KJ, Wang XY and He DL: A novel anti-cancer effect of genistein: reversal of epithelial mesenchymal transition in prostate cancer cells. Acta Pharmacol Sin 29: 1060-1068, 2008.

25 Wu K, Zeng J, Li L, Fan J, Zhang D, Xue Y, Zhu G, Yang L, Wang $X$ and He D: Silibinin reverses epithelial-to-mesenchymal transition in metastatic prostate cancer cells by targeting transcription factors. Oncol Rep 23: 1545-1552, 2010.

Received October 29, 2018

Revised November 11, 2018

Accepted November 13, 2018 